\title{
Thermal Analysis of Extended surfaces from the Heat sink of Different shape - A Brief Review

\author{
Alok Kumar ${ }^{1}$, Dr. Ajay Singh ${ }^{2}$, Prof. Ashish Verma ${ }^{3}$ \\ ${ }^{1}$ PG Scholar Department of Mechanical Engineering, Radharaman Institute of Technology and Science, Bhopal, Madhya \\ Pradesh. India \\ ${ }^{2}$ Professor and Head Department of Mechanical Engineering, Radharaman Institute of Technology and Science, Bhopal, \\ Madhya Pradesh. India \\ ${ }^{3}$ Assistant Professor, Department of Mechanical Engineering, Radharaman Institute of Technology and Science, Bhopal, \\ Madhya Pradesh. India
}

\section{Article Info \\ Volume 8, Issue 5 \\ Page Number : 285-292}

Publication Issue :

September-October-2021

Article History

Accepted : 10 Oct 2021

Published: 30 Oct 2021

\section{ABSTRACT}

This paper introduces a brief review about the way of heat extraction enhancement from heat sink using fins of different types and different shapes and also with different shape of perforation. Extended surfaces from the base plate or heat sink is nothing but they are FINS. There are various types of fin exits. They are Rectangular, Square, Annular, Elliptical, Cylindrical or Pin fin which is utilized with different geometrical combinations. To achieve maximum temperature droop from the base surface or heat sink by using fins numerous trials are completed or being carried out for designing optimized Fin. The optimization of Fin can be achieved by increasing surface contact area with the atmospheric air. In these days there are numbers of experiment is done on fins like Solid fin, Porous fins and Solid fins with perforation, has also been brought off. The various design modifications which are implemented and studied analytically and experimentally by the researchers using ANSYS Work bench is been discussed in this review paper.

Keywords - Extended surface, Fin, Perforation, Heat sink, ANSYS Work bench

\section{INTRODUCTION}

Fins are extensively used in IC engine as extended surface in cylinder head of air cooled engine and compressor and on electric motor body. In air conditioner and radiator tubes with circumferential fins are used to increase the heat flow. Electronic chips cannot function without use of fin to dissipate the heat generated. Increment of heat transfer is of essential in much industrial exercise. There are two techniques for enhancing the heat transfer from the heat sink [1].

\section{Active Method \\ 2. Passive Method}

In the design point of view, active methods are complex as they require some extraneous power input 
for necessary flow adjustments and to boost the heat transmit rate and thus applications are limited. However, passive methods require geometrical or surface adjustments to the flow passage by incorporating additional devices [1]. There are numerous situations where heat is to be transferred between fluid and surfaces. In such cases heat flow depends on three factors such as

\section{i. Area of the surface \\ ii. Temperature difference and \\ iii. The convective heat transfer coefficient.}

The bottom area is bounded by design of the system. The temperature gap rely on the procedure and cannot be revamped.The solitary solution seems to be convection heat transfer coefficient and this cannot be hiked over a certain value. Any such hike will be at levy of power for fan or pump. Thus the possible action is to raise the bottom area by so called elongated surfaces or fins. The fin lengthens from base surfaces and provides additional surface area for the heat conducted into the fin at the base. Fins are thus used whenever the available surface area is found insufficient to transfer the require quantity of heat with the available temperature deep and heat transfer coefficient Major Types of fins are in used Shown in fig. 1. They are- a. Plate fin of constant sectional area. b. Plate fin of variable sectional area. c. Annular or circumferential fin of constant thickness d. Pin fin of variable sectional area [13].
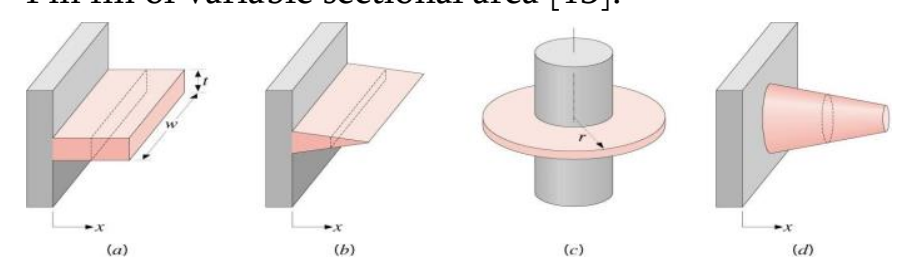

Fig. 1

The main aim of the study is to design fin to optimize the use of a given amount of material to maximize heat transfer. For this purpose it will be desirable that the fin surface temperature is closer to the base surface temperature. This can be pulled of by the use of material of high thermal conductivity like copper or aluminum. As copper has low thermal conductivity in comparison to aluminum but even then later is used due to its low weight and ease of lubrication.

\section{Literature Review}

Ambarish Maji et al. [1] "Improvement of heat transfer through fins: A brief review of recent developments". This review paper presents a review on heat transfer increment using fins different types of fin like porous, perforated. Porous fins transfer better heat as compared with solid ones of the same size and weight by increasing the area of convection. The perforated fins have much higher contact surface with the fluid possessed to it with compare to solid fins. They also proposed the used of different material such as aluminum, HSS, copper. They concluded that using perforation of different geometries also influence the transmission of heat through fins. Variation of Reynolds number, Nusselt number, and pressure drop can be analyzed through fins with variable perforations and these can be compared with a no perforated fin. The fin with smaller perforations gives a better thermal transmission. The micro pin fin surface has a better thermal transmission rate than the smooth surface. $\mathrm{CHF}$ as well as heat transfer coefficient also increases in the composite micro/nano-structured surface rather than the smooth surface. On the other hand, CHF and heat transfer performance is much more effective around a bi-structured surface.

Abdul Razak Kaladgi et al. [2] "Heat transfer enhancement of rectangular fins with circular perforations". The focus of this paper is to inspect the temperature suppression over a variety of round perforations. Integral simulation (ANSYS Fluent cipher) is implemented to explore fins with perforations. A FVM cipher is brought to solve turbulent air flow and heat transfer equations across fins. For round perforation counts, other variables such as heat flux and thermal gradient are differentiated. It was discovered that there was remarkable temperature suppression as well as rectification in thermal transmission. The outcome can be broadened to the design of rectangular fin thermal exchangers. 
Rajat Kumar et al.[3] "Static Thermal Analysis Of Fins Models Using ANSYS" In the current exertion, Evaluations have been conducted to come across the temperature alteration inside the fins made in four kind geometries (plate Fins, Round Pin fins, plate fins with holes, and draft Pin fins) and consistent state heat exchange examination has been studied utilizing a finite element software ANSYS to test and approve results. The temperature alterations at several areas of fins replica are assessed by FEM and differentiate models of fins capability by heat flux and temperature alterations obtained by experimentally in Analysis. The idea administered in this project is to scale up the heat exhaust rate by employing the wind flow. The ultimate purpose of the inquiry is to augment the thermal properties by rearranging geometry, material, and design of fins. Following parameters is considered. They took Plate FinBase dimension $-(1 \times b \times h)=80 \times 70 \times 10 \mathrm{~mm}$ Plate Fin dimension- $64 \times 10 \times 75 \mathrm{~mm}$ Rectangular fin with hole dimension- $64 \times 10 \times 75 \mathrm{~mm}$ Hole diameter- $3 \mathrm{~mm}$ Round Pin Fin- Diameter- $6 \mathrm{~mm}$ Length-75mm Draft Pin Fin dimension- Diameter-6 mm Taper at $0.80^{\circ}$ Above dia-1.82 mm. Through The comparative analysis using ANSYS of plate concluded that fin, Round Pin Fin and Plate Fins with hole \& Draft Pin Fin is found that using conical draft fin with material aluminum alloy 1060 is better since the temperature drop and the heat transmission rate in a conical draft pin fins much more compare to other the three fins Plate fin, Rectangular fin.

Nabeel Abdulhadi Ghyadi et al.[4] "Enhancement of Forced Convection Heat Transfer from Cylindrical Perforated Fins Heat Sink-CFD Study" In this exegesis, the three-dimensional, nonisothermal CFD model has been flourished for the objective of interpreting thermal performance of heat sink with perforated fins. Four patterns of pin fin heat sinks with distinct geometrical patterns were brought. The commanding equations were discretized using a finite-volume method (FVM) and solved using multi-physics COMSOL package v. 5.3 and corroborated with accessible experimental outcome. CFD results were in accordance with the experimental consequences, exhibiting dependability related to CFD simulation model registered in this exegesis. Consequences have revealed that the perforated pin fins improve the heat dissipation rate and furnish ample and affordable improvement in the thermal transmission.

Vidyadhar Karlapalem et al. [5] "Design of perforated branching fins in laminar natural convection" In this paper Optimum design of branching fin with round perforation is examined Under laminar natural convection conditions which is used for electronic cooling application. Round perforations with diameters altering between 1.1 $\mathrm{mm}$ and $6.6 \mathrm{~mm}$ are used. In this size range, the surface area of the perforated fins is less than the non-perforated fins. There are two acclimatization of the fins are taken, namely vertical base horizontal fin (vBhF) and horizontal base vertical fin $(\mathrm{hBvF})$. Having a 'single' perforated branching fin, heat extraction is always elevated by making perforations in $\mathrm{vBhF}$ direction, but it would suppress in $\mathrm{hBvF}$ orientation for certain hole sizes and arrangements. The whole analysis is carried out by using ANSYS fluent. Through this investigation, he found that Perforations in $\mathrm{vBhF}$ orientation result in heat transfer enhancement over solid fins, at any pore size and arrangement. Certain pore distributions result in lesser heat transfer than that of the non-perforated fins in $\mathrm{hBvF}$ orientation. This is due to weaker contribution from the pores in the fin-stem, which are normal to the buoyant flow direction.

Abhishek Jha et al. [6] "Thermal Analysis of Different Perforated Pin Fins By Using ANSYS". In this paper researcher investigated solid Pin Fin with different type of perforation such as round, rectangular and square hole using ANSYS. They considered the dimension of fin as follows Pin finDimension Length $=90 \mathrm{~mm}$ Diameter $=8 \mathrm{~mm}$ Round Hole Diameter $=4 \mathrm{~mm}$ Rectangular hole length \&breath $=6 \mathrm{~mm} \& 4 \mathrm{~mm}$ Triangular hole length $\&$ Breath $=4 \mathrm{~mm} \& 4 \mathrm{~mm}$. Pin fin used in this analysis is of aluminum alloy. They concluded that Solid pin fin with rectangular holes perform better than all other with different holes. 
P. Senthilkumar et al.[7] "Design and thermal analysis on round fin". In this paper researchers investigated the temperature distribution along the round fin of rectangular, trapezoidal, elliptical and triangular profile of two stroke SI engine. The material used is of aluminum. The whole analysis is performed using ANSYS. They concluded that the Triangular profile fins shows better temperature suppression than other shape of fin with respect to their length and elliptical fins having less space between them can give better performance than the parent sample. The elliptical fin thermal transmission analysis only based on design parameters which is space between the cross section of fins.

G. Naresh et al. [8] "Steady State Thermal Analysis on Heat Sinks by Varying Fin Configuration using ANSYS" In this paper, a comparative thermal analysis on heat sinks of different configurations is performed. The aim in this research is to determine the optimal design for a heat sink to decrease the temperature more by natural convection. Designing part is done using Solid Works software. The designed models are analyzed using ANSYS WORKBENCH. The results obtained suggest the Rectangular flat plate heat sink as optimum design among the considered heat sink models. In this research, there is comparison is done among rectangular plate fin, staggered fin, round pin fin, elliptical fin. They obtained that there is more temperature droop along the rectangular fin compare to others.

Varun R. Yadav et al. [9] "Experimental Analysis to Investigate the Thermal Performance of Different Types of Fin Geometry" The main aim in this paper is to analyze the steady state thermal performance of various types of fin geometry .They used rectangular, round and trapezoidal fin to investigate temperature distribution along the fin by using experimental method. The rectangular fin Dimension $=10 \mathrm{~mm}$ and $20 \mathrm{~mm}$ from the root of fin. Round fin Diameter $5.64 \mathrm{~mm}$ \& Length of 22.57 $\mathrm{mm}$ from root of fin From the experimental analysis it has been observed that the temperature distribution for the triangular fins is more uniform then the fins of different geometry having the same base temperature.

N. Raja Sekhar et al. [10] "Design and Thermal Analysis of IC Engine Fins for Effective Heat Transfer by Modifying Material and Geometry". In this paper researcher investigated the temperature distribution and heat flux along the rectangular and triangular fin of different material such as Aluminum Alloy- AL 6063, AL 6063T5 and AL 6063T6.they analyzed the Honda $100 \mathrm{cc}$ engine using different fin on peripheral of it . The whole analysis is brought out using ANSYS. They concluded that the thermal gradient or the rate of thermal flow per unit length is observed more in the triangular fins than in Rectangular fins. From this analysis it has been noticed that the thermal flux through the Triangular fins is more when compared with Rectangular shape in AL 6063, AL 6063 T5 and AL 6063 T6 at same thickness.

Suhil Kiwan et al. [11] "An experimental investigation of the natural convection heat Transfer from a vertical cylinder using porous fins" This paper introduce the thermal impact of annular porous fins which is attached to the exterior of a hanged hot upstanding cylinder with constant thermal flux was experimentally examined. The evaluation occurred under steady-state and natural convection conditions. They chose aluminum cylinders of three variable diameter and also two variety of spongy substance were employed with various fin layout like fin thickness and number of fins.

Abdul Toufique et al. [12] "CFD Analysis of Plate Fin Heat Exchanger By using ANSYS". In this analysis plate fin heat exchanger is analyzed with various thickness of the plate in plate thermal transmission varies from $3.5 \mathrm{~mm}, 5 \mathrm{~mm}$, and 6.5 $\mathrm{mm}$, and two types of material copper, structural steel is employed. From the analysis using ANSYS, results outcomes show that, if we increase the thickness from $3.5 \mathrm{~mm}$ to $6.5 \mathrm{~mm}$ than our steel material has better thermal transmission in plate fin heat exchanger.

L. Prabhu et al. [13] "Design and Analysis Of different types Of Fin configurations using ANSYS". In this paper researcher analyzes different types of solid fin such as rectangular, square and round. Aluminum is selected as fin materials. Fins are designed by using CATIA and the analysis is processed by using ANSYS Workbench. By doing this analysis they found that there is more temperature drops along the rectangular Fin with compare to round and square. The effectiveness of the fin with rectangular configuration is greater than other configuration. 
R. Sudheer kumar Reddy et al. [14] "Thermal Analysis of Pin Fin with Different Shape Forms using ANSYS". In this paper researchers investigated the effect of different types of fin on the heat sink. The analysis is done using ANSYS of solid and hollow round fin with round perforation. The fins are used for analysis is of different materials such aluminum, copper, stainless steel, brass. By doing this analysis they concluded along the length of perforated fin there is large amount of temperature drop in comparison to non perforated fins.

L.Natrayan et al. [15] "Thermal Analysis of Engine Fins with Different Geometries"

The purpose of the existing exegesis is to look over the thermal effect by varying geometry of cylinder fins using ANSYS work bench. The 3D model of the cylindrical fins is designed by using SOLIDWORKS 2016 and its thermal effects are being probed by utilizing ANSYS workbench R 2016. For the ongoing exegesis material utilized for production of cylinder fin body is Aluminum Alloy AA 6061 which has thermal conductivity of $160-$ $170 \mathrm{~W} / \mathrm{mk}$. They concluded that wavy fin shaped cylinder block can be used for increasing the heat transfer from the fins by creating turbulence for upcoming air. Improvements in heat transfer can be comparing with all the four model of the engine fins geometry by CFD Analysis and its flow.

Sachin Kumar Gupta et al. 16] "Thermal Analysis of various perforated Tree Shaped Fin Array using ANSYS". The present paper discusses the possibility of using different types of perforated and non-perforated tree fin array as a fin for a processor in a computer terminal. The investigation is conducted to compare heat transfer from arrays of Tree fins without and with different perforations. This would be attained by 3D pattern and inspecting by employing ANSYS, 14.5. The motive is to elevate the thermal transmission rate from the fin contour and economizing material value. Due to less use of materials and energy encourage for the development of improved methods. Researchers concluded that the array of tree fins with 12 number of perforation having a better thermal transmission capability when compared to a tree fin without perforation and with 6 number of perforation. Aluminum alloy can be used in the shape of tree fins with greater number of perforation as a heat sink for an effective transfer of heat being generated. It is concluded that the maximum heat transfer rate will takes place in 12 square perforation tree fins.

Hisham H. Jasim et al.[17]"Thermal Enhancement from Pin Fins by Using Elliptical Perforations with Different Inclination Angles" In the present paper rectangular pin fins consist of elliptical perforations with two models and two cases. They concluded that increasing the inclination angle, perforation size, and number of perforations leads to decrease in the temperature of the fin for the following reasons:

a. Increase of the inner convection area. b. Distribution of the inner convection area on the longer length on the $y$-axis. c. Increase of the external perforated area. d. The conduction area that is replaced by the convection area was increased.

Amer Al-Damook et al. [18] "An experimental and computational investigation of thermal air flows through perforated pin heat sinks". An analytical heat sink with many perforations is constructed and created and variables study the effect of perforated pin fin design on thermal transmission and pressure drops across the heat sinks. Experimental statistics is found to grant well with predictions from a CFD for the associate thermal transmission into the cooling air stream. The authenticated CFD model is employed to execute a parametric research of the impact of the number and positioning of ring shaped perforations, which is showing that the Nusselt number raise monotonically with the number of pin perforations, while the pressure descend and fan power required to conquer the pressure descend all reduce monotonically Pins with five perforations are shown to have a $11 \%$ larger $\mathrm{Nu}$ than for corresponding solid pin cases. These benefits emerge due to not only the augmented surface area but also thermal transfer enrichment near perforations along the establishment of localized air jets. By the present work researchers concluded that the use of multiple pin perforations can have substantial performance benefits by entitling the thermal transfer to be elevated while at the same time reducing both the pressure drop along the heat sink and fan power needed to pump the air through them.

Rasika Mhatre et al. [19] "CFD Analysis of Perforated FINS". In this paper they had designed 
different perforated fin geometries like slotted fin, inclined perforated fin, taper with inclination fin, spine fin. CFD analysis of these fins is done using ANSYS CFX for the constant heat flux and performance of these fins are evaluated. They concluded that thermal analysis of spine with hole fin, slotted fin and taper with extension fin, slotted fin gives better results. Considering lower velocity of $1 \mathrm{~m} / \mathrm{s}$ slotted fin and spine with hole fins are giving nearly same heat dissipation. At highest velocity of $8 \mathrm{~m} / \mathrm{s}$ slotted fin gives better thermal transmission rate than rest two fins. Out of total 5 fins, inclined perforated fin gives better thermal transmission rate. There is $12.34 \%$ of increase in heat transfer rate in Inclined Perforated fin as compared to Rectangular fin. Nusselt no. is a function of heat transfer coefficient. At lower velocity of $1 \mathrm{~m} / \mathrm{s}$ flow causes no change or slightly increases in heat transfer rate. At higher velocity $8 \mathrm{~m} / \mathrm{s}$ higher collision of fluid particles take place.

\section{Conclusions and Future Scope}

This paper represents a review of enhancing heat transfer using different fins. By going through all the paper on fins I observe that there are numbers of modification is done by the researchers. All that modifications are done on the basis of material selection and geometrical design. Several ways and techniques have been developed by researchers in order to enhance the heat transfer by Fins. Many researchers investigated on the basis of materials. They used aluminum, copper, stainless steel, brass. They found that in materials of fins aluminum proved to be more efficient than other materials. Many researchers introduce notches and slots (perforation) on the solid fins. They found that increase in temperature drop along the length of fins. But till now very less research is done on the hollow fins with perforation so there is scope to do research considering it. From the extensive literature study on fins, some interesting findings by the authors are summarized below:

- Porous fins transfer better heat as compared with solid ones for the same size and weight by increasing the surface area for convection. This justifies their use in applications where weight is a major constraint.
- Using perforation of different geometries also affects the heat transfer through fins. Variation of Reynolds number, nusselt number, and pressure drop can be analyzed through fins with variable perforations and these can be compared with a no perforated fin. The fin with smaller perforations gives a better thermal transmission.

- Pin fins of elliptical geometry can also improve the rate of heat transfer as compare to other geometry like annular and eccentric.

- Solid fins with rectangular notch have greater heat transfer rate compared to that of fins without hole.

- It is also observed that branching in fins and introducing hole further increase the efficiency and effectiveness of fins.

- Fins with more thickness results in increase of heat transfer compare to less thickness.

- With increase in the number of holes on the periphery of fins also improves the rate of heat transfer from the base surface.

- In forced convection when the velocity of air is increase there is increase in temperature drop along the length of the fins.

\section{REFERENCES}

[1]. A. Maji and G. Choubey, "Improvement of heat transfer through fins: A brief review of recent developments," Heat Transfer, vol. 49, no. 3, pp. 1658-1685, Feb. 2020

[2]. A. R. Kaladgi, F. Akhtar, S. P. Avadhani, A. Buradi, A. Afzal, A. Aziz, and C. Ahamed Saleel, "Heat transfer enhancement of rectangular fins with circular perforations," Materials Today: Proceedings, May 2021.

[3]. R. Kumar, D. Singh, and A. K. Sharma, "Static Thermal Analysis Of Fins Models Using Ansys," May 2020

[4]. Nabeel Abdulhadi Ghyadh, Sahib Shihab Ahmed, " Enhancement of Forced Convection Heat Transfer from Cylindrical Perforated Fins Heat Sink-CFD Study", Journal of Mechanical Engineering Research and Developments, Vol. 44, No. 3, pp. 407-419, 2021 
[5]. V. Karlapalem and S. K. Dash, "Design of perforated branching fins in laminar natural convection," International Communications in Heat and Mass Transfer, vol. 120, p. 105071, Jan. 2021.

[6]. Abhishek Jha, Prateek Gupta, "Thermal Analysis of Different Perforated Pin Fins Using ANSYS", Journal of Material Science and Mechanical Engineering (JMSME) Vol. 5, Issiue 2, April-June 2018 pp.71-76,ISSN:2393-9095.

[7]. Senthilkumar, P., S. Rajesh Babu, B. Koodalingam, and T. Dharmaprabhakaran. "Design and Thermal Analysis on Circular Fin." Materials Today: Proceedings 33 (2020): 29012906. doi:10.1016/j.matpr.2020.02.784.

[8]. G. Naresh , G. Akhil Sai "Steady State Thermal Analysis on Heat Sinks by Varying Fin Configuration Using ANSYS", Mukt Shabd Journal, Volume IX, Issue IV, APRIL/2020, ISSN NO : 2347-3150

[9]. Varun R.Yadav, Karan S. Vishe, “ Experimental Analysis to Investigate the Thermal Performance of Different Types of Fin Geometry" , International Research Journal of Engineering and Technology (IRJET) Volume: 06 Issue: 02 | Feb 2019, e-ISSN: 2395-0056

[10]. N. Raja Sekhar, Dr.V.Lakshmi kanth Chowdary, "Design and Thermal Analysis of IC Engine Fins for Effective Heat Transfer by Modifying Material and Geometry", International Journal Of Research In Aeronautical And Mechanical Engineering, Vol.8 Issue 6, June 2020 Pg: -1222, ISSN: 2321-3051

[11]. S. Kiwan, H. Alwan, and N. Abdelal, "An experimental investigation of the natural convection heat transfer from a vertical cylinder using porous fins," Applied Thermal Engineering, vol. 179, p. 115673, Oct. 2020.

[12]. Abdul Taufiq, P. S. Dhakar, " CFD ANALYSIS OF PLATE HEAT EXCHANGER BY USING ANSYS”, International Journal of Research and
Analytical Reviews, Volume7, Issue3, September 2020, ISSN 2348-1269

[13]. L.Prabhu, M.Ganesh Kumar, "Design And Analysis Of Different Types Of Fin Configurations Using ANSYS”, International Journal of Pure and Applied Mathematics Volume 118 No. 5 2018, 1011-1017 ISSN: 13118080 (printed version); ISSN: 1314-3395 (online version)

[14]. R. Sudheer kumar Reddy, Dr .k. Govinda Rajulu, "Thermal Analysis of Pin Fin with Different Shape Forms using ANSYS", International Journal of Engineering Science and Computing, VOLUME 7 ISSUE NO.-5, May 2017

[15]. V L.Natrayan, G.Selvaraj, N.Alagirisamy, Thermal Analysis of Engine Fins with Different Geometries" , International Journal of Innovative Research in Science, Engineering and Technology, Vol. 5, Issue 5, May 2016, DOI: 10.15680/IJIRSET.2016.0505040

[16]. Sachin Kumar Gupta, Rahul Singh, Divyank Dubey, "Thermal Analysis of various perforated Tree Shaped Fin Array usingANSYS”, Research Gate ,www.researchgate.net/ publication /339473370, January2015

[17]. H. H. Jasim and M. S. Söylemez, "Thermal Enhancement from Pin Fins by Using Elliptical Perforations with Different Inclination Angles," Heat Transfer-Asian Research, vol. 47, no. 1, pp. 165-184, Aug. 2017.

[18]. A. Al-Damook, N. Kapur, J. L. Summers, and H. M. Thompson, "An experimental and computational investigation of thermal air flows through perforated pin heat sinks," Applied Thermal Engineering, vol. 89, pp. 365376, Oct. 2015.

[19]. Rasika Mhatre, Vishakha Pathari, "CFD Analysis Of Perforated FINS" International Journal of Advanced Research in Science \& Technology (IJARST) Volume 7, Issue 3, July 
2020 ,ISSN (Online) 2581-9429, DOI:

XX.072020/IJARST

\section{Cite this article as :}

Alok Kumar, Dr. Ajay Singh, Prof. Ashish Verma, "Thermal Analysis of Extended surfaces from the Heat sink of Different shape - A Brief Review", International Journal of Scientific Research in Science, Engineering and Technology (IJSRSET), Online ISSN : 2394-4099, Print ISSN : 2395-1990, Volume 8 Issue 5, pp. 285-292, September-October 2021. Available at doi : https://doi.org/10.32628/IJSRSET218540 Journal URL : https://ijsrset.com/IJSRSET218540 